\title{
ACUTE APPENDICITIS DURING PREGNANCY: NO PLACE FOR MAYBE
}

\author{
Ionuț Negoi $^{1,2}$, Sorin Păun ${ }^{1,2}$, Sorin Hostiuc ${ }^{1,3}$, Alin Moldoveanu ${ }^{4}$, Mircea Beuran ${ }^{1,2}$ \\ ${ }^{1}$ Carol Davila University of Medicine and Pharmacy Bucharest, Romania \\ ${ }^{2}$ General Surgery Department, Emergency Hospital of Bucharest \\ ${ }^{3}$ National Institute of Legal Medicine Mina Minovici \\ ${ }^{4}$ Polytechnic University of Bucharest, Faculty of Automatic Control and Computers, Bucharest, Romania. \\ Corresponding author: Ionuț Negoi \\ Phone no. 0040215992308 \\ E-mail: negoiionut@gmail.com
}

\begin{abstract}
Acute appendicitis is the most common abdominal non-obstetrical emergency in pregnant women; its management however is supported by a low level of evidence. The main objective of this study was to evaluate the clinical management of pregnant women with acute appendicitis. We have reviewed the hospital database selecting the pregnant women with acute appendicitis managed in the last 24 months. 8 appendectomies were performed in pregnant women. Mean age was $27.2 \pm 6.1$ years. All patients had a history of right lower abdominal pain of 36 hours or less. General anesthesia was used in $12.5 \%$ of cases and spinal anesthesia in the remaining of cases. In all cases appendectomy was performed through a McBurney's incision with a mean operating time of 36.25 minutes. There was no maternal or fetal mortality.The diagnosis of acute appendicitis is challenging in pregnant women. A prompt, but a non-negative appendectomy should always be aimed, and no unecessary risks should be taken.
\end{abstract}

Keywords: acute appendicitis, pregnancy, surgery

\section{Introduction}

Acute abdominal pathologies with nonobstetrical causes are found in about one to 500 -700 pregnancies, $0.2-2 \%$ of cases requiring a surgical intervention [1]. For these patients the clinical picture is often unclear and nonspecific, with a difficult differential diagnosis [2-4]. The surgeon, either gynecologist or emergency specialist should always remember that any delay in diagnosis can put both, the mother and the fetus at significant risks. Current evidence shows that in pregnant women the risk of premature delivery is increased both by the perforation of the appendix, and by negative appendectomies [5].
The main objective of this study was to evaluate the clinical picture and the outcomes in pregnant women with a surgical procedure for acute appendicitis.

\section{Materials and methods}

We have reviewed the hospital database, selecting pregnant women that suffered a surgical procedure for acute appendicitis in the last 24 months. We recorded the following data: demographics, clinical data, imagistic findings, operative data and early morbidities. We used descriptive statistics, using SPSS version 2.0 for Mac as statistical software. 


\section{Results}

Eigth appendectomies were performed in pregnant women during the study interval of 24 months.

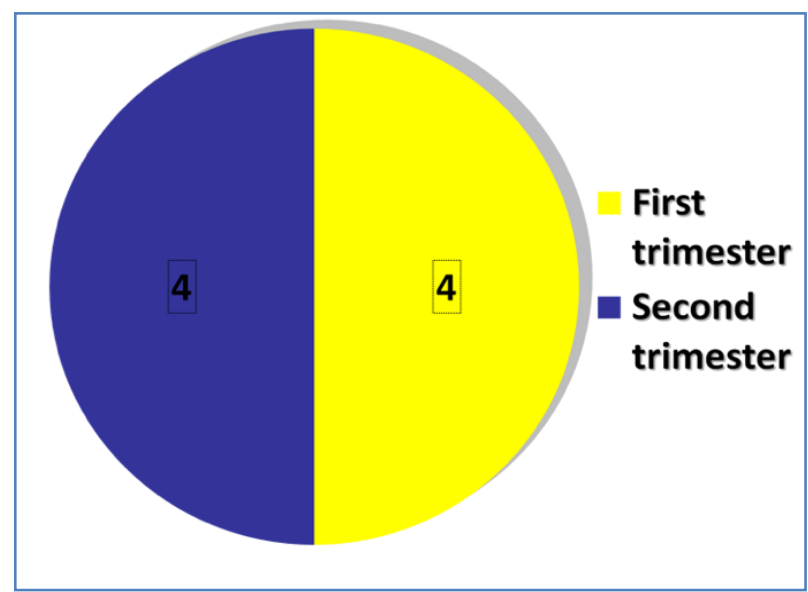

Figure 1 - Gestational age at presentation

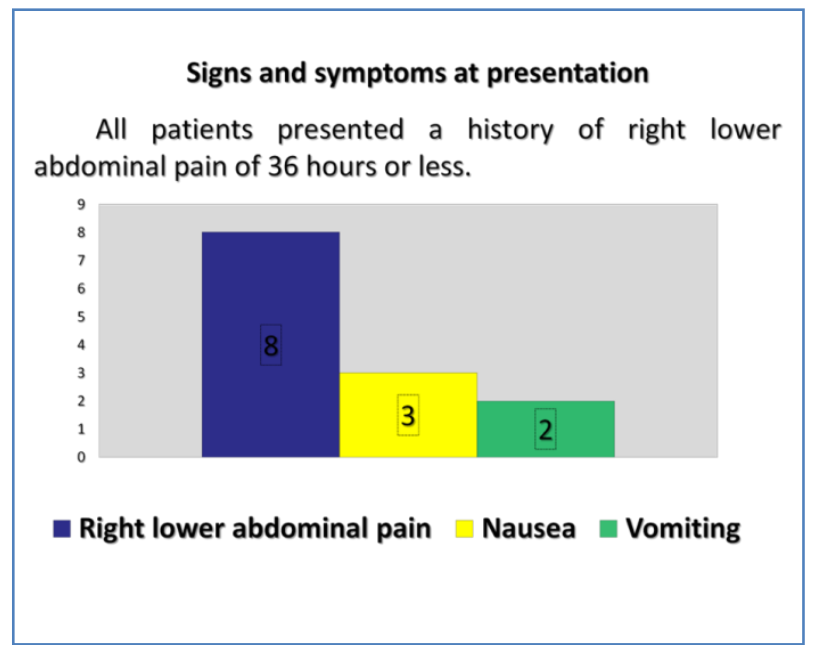

Figure 2 - Clinical picture at admission.

\section{Ultrasound sensibility for visceral lesion}

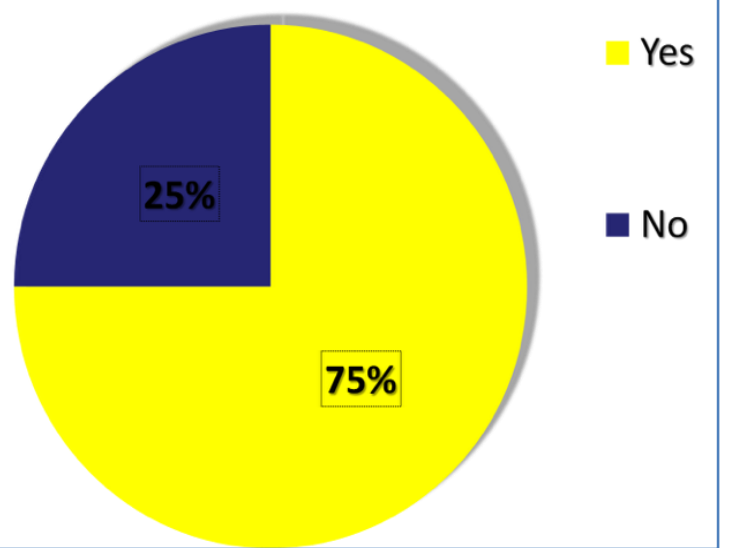

Figure 3 - Ultrasound sensibility regarding detection of visceral pathology.
Mean age was $27.2 \pm 6.10$ years. All patients had a history of right lower abdominal pain of 36 hours or less. The general anesthesia was used in one case and spinal anesthesia in the remaining seven. In all cases appendectomy was performed through a McBurney's incision with a mean operating time of 36.25 minutes. There was no maternal or fetal mortality. The most common signs and symptoms at presentation were right lower abdominal pain, nausea and vomiting (Figure 2).

Ultrasound properly identified the appendicitis in six cases (75\%) (Figure 3).

\section{Discussions}

The incidence of acute appendicitis decreases during pregnancy, the third trimester being associated with the lowest risk [6]. According to Zingone et al. the frequency of acute appendicitis is 53\% lower during the last trimester in pregnant compared to non-pregnant women [6].

A population-based study, including 7.114 women with appendicitis among 7.037.386 births, showed a twofold increase in the risk for sepsis, septic shock, transfusion, pneumonia, bowel obstruction, postoperative infection, and length of stay > three days for pregnant, compared to non-pregnant women with appendicitis [7].

A nationwide study coming from Taiwan, which compared women with and without acute appendicitis during pregnancy found a higher risk for low birth weight - OR $=1.82$ $(95 \% \mathrm{CI}=1.43$ to 2.30$)$, preterm birth $-\mathrm{OR}$ $=1.59(95 \% \mathrm{CI}=1.25$ to 2.02$)$, small for gestational age, $\mathrm{OR}=1.33 \quad(95 \% \mathrm{CI}=1.12$ to 1.60), cesarean section $\mathrm{OR}=1.24(95 \% \mathrm{CI}=1.07$ to 1.44 ), and congenital anomalies $\mathrm{OR}=2.07$ $(95 \% \mathrm{CI}=1.07$ to 4.03$)$ [8].

Abbasi, by comparing patients with appendicitis and delivery during the same inhospital stay with patients with delivery but without appendicitis has found a higher risk of preterm delivery for the first subgroup (OR = $2.68,95 \% \mathrm{CI}=2.31$ to 3.11 ) [9].

The examining physician should always be aware of the difficulty in diagnosis of acute appendicitis in pregnancy. Although we didn't use it in any of the eight presented cases, the 
Magnetic Resonance Imaging (MRI) seems to be very useful and reproducible in this setting [10]. For example $\mathrm{Vu}$ et al. investigated the accuracy of MRI in 19 pregnant patients with unclear ultrasonography (US) findings but with a clinical suspicion of acute appendicitis [11]. The MRI suggested acute appendicitis only in one case, who was certified by the surgery and pathology report [11]. Oto et al. found that MRI as a diagnostic tool for pregnant patients with acute abdominal pain has a sensitivity of $90 \%$, a specificity of $98.1 \%$ and an overall accuracy of $97.5 \%[12]$.

In an article published by Israel et al the evaluation of pregnant patients with acute appendicitis was superior with MRI compared to ultrasound. Even in cases with an observable appendix, the sensitivity and negative predictive values of MRI were higher $(100 \%$ versus $50 \%$ and $100 \%$ versus $66 \%$, respectively) [13].

According to the latest European Association for Endoscopic Surgery Consensus Conference, from 2015, the laparoscopic approach should be preferred in all patients with acute appendicitis [14]. In pregnant women with acute appendicitis the level of evidence supporting the surgical approach is low. Although laparoscopy has the benefit of identifying other intra-abdominal pathologies, some studies suggest a higher risk for fetal loss with this approach [15]. In their study of 3133 pregnant patients from a group of 94789 appendectomies, McGory et al. found on multivariate analysis that complicated disease $(\mathrm{OR}=2.69)$ and negative disease $(\mathrm{OR}=1.88)$ are predictors for fetal loss [15].

A comparison of laparoscopic with open approach in acute appendicitis during pregnancy found no difference in fetal loss, APGAR score, birth weight and preterm delivery. The negative prognostic factors were maternal temperature greater than 38 degrees Celsius, leucocytes > $16000 / \mathrm{mmc}$, and $>48$ hours from the onset of symptoms to hospital admission [16].

A systematic review of the literature comparing open approach to laparoscopic in pregnant patients, published in 2014, concluded that there is no strong evidence to support any of it from the point of fetal or maternal safety [17]. Although this systematic review showed a higher rates of fetal loss in laparoscopic group [17], for maternal outcomes, a population based study published in Surgical Endoscopy this year concluded that surgery should be preferred to nonoperative approach, and that laparoscopy offers the same maternal complication rate as the open approach [18].

\section{Conclusions}

The diagnosis of acute appendicitis is challenging in pregnant patients. A prompt, but a non-negative appendectomy should always be aimed, leaving no place for unnecessary additional risks.

\section{References}

[1]Bouyou J, Gaujoux S, Marcellin L, Leconte M, Goffinet F, Chapron C, et al. Abdominal emergencies during pregnancy. J. Visc. Surg. [Internet] 2015 [cited 2015 Nov 30];152:S105-15. Available from:

http://www.ncbi.nlm.nih.gov/pubmed/26527261

[2]Malangoni MA. Gastrointestinal surgery and pregnancy. Gastroenterol. Clin. North Am. [Internet] 2003 [cited 2015 Dec 9];32:181-200. Available from:

http://www.ncbi.nlm.nih.gov/pubmed/12635416

[3]Flexer SM, Tabib N, Peter MB. Suspected appendicitis in pregnancy. Surgeon [Internet] 2014 [cited 2015 Dec 14];12:82-6. Available from: http://www.ncbi.nlm.nih.gov/pubmed/24429161

[4] Stukan M, Kruszewski WJ, Dudziak M, Kopiejć A, Preis K. [Appendicitis and gall bladder diseases as acute abdominal conditions in pregnancy]. Ginekol. Pol. [Internet] 2013 [cited 2015 Dec 14];84:1045-50. Available from: http://www.ncbi.nlm.nih.gov/pubmed/24505953

[5]Aggenbach L, Zeeman GG, Cantineau AEP, Gordijn SJ, Hofker HS. Impact of appendicitis during pregnancy: no delay in accurate diagnosis and treatment. Int. J. Surg. [Internet] 2015 [cited 2015 Dec 14];15:84-9. Available from: http://www.ncbi.nlm.nih.gov/pubmed/25638737 [6]Zingone F, Sultan AA, Humes DJ, West J. Risk of acute appendicitis in and around pregnancy: a population-based cohort study from England. Ann. Surg. [Internet] 2015 [cited 2015 Nov 11];261:332$7 . \quad$ Available from: http://www.ncbi.nlm.nih.gov/pubmed/24950289

[7]Abbasi N, Patenaude V, Abenhaim HA. Management and outcomes of acute appendicitis in pregnancy-population-based study of over 7000 cases. BJOG [Internet] 2014 [cited 2015 Dec 
14];121:1509-14. Available from: http://www.ncbi.nlm.nih.gov/pubmed/24674238

[8]Wei P-L, Keller JJ, Liang H-H, Lin H-C. Acute appendicitis and adverse pregnancy outcomes: a nationwide population-based study. J. Gastrointest. Surg. [Internet] 2012 [cited 2015 Dec 14];16:120411. Available from: http://www.ncbi.nlm.nih.gov/pubmed/22402956

9. Abbasi N, Patenaude V, Abenhaim HA. Evaluation of obstetrical and fetal outcomes in pregnancies complicated by acute appendicitis. Arch. Gynecol. Obstet. [Internet] 2014 [cited 2015 Dec 14];290:661-7. Available from: http://www.ncbi.nlm.nih.gov/pubmed/24838290 [10]Burke LMB, Bashir MR, Miller FH, Siegelman ES, Brown $M$, Alobaidy $M$, et al. Magnetic resonance imaging of acute appendicitis in pregnancy: a 5-year multiinstitutional study. Am. J. Obstet. Gynecol. [Internet] 2015 [cited 2015 Dec 14];213:693.e1-6. Available from: http://www.ncbi.nlm.nih.gov/pubmed/26215327 [11]Vu L, Ambrose D, Vos P, Tiwari P, Rosengarten M, Wiseman S. Evaluation of MRI for the diagnosis of appendicitis during pregnancy when ultrasound is inconclusive. J. Surg. Res. [Internet] 2009 [cited 2015 Dec 14];156:145-9. Available from:

http://www.ncbi.nlm.nih.gov/pubmed/19560166

[12]Oto A, Ernst RD, Ghulmiyyah LM, Nishino TK, Hughes D, Chaljub G, et al. MR imaging in the triage of pregnant patients with acute abdominal and pelvic pain. Abdom. Imaging [Internet] [cited 2015 Dec 14];34:243-50. Available from: http://www.ncbi.nlm.nih.gov/pubmed/18330616 [13]Israel GM, Malguria N, McCarthy S, Copel J, Weinreb J. MRI vs. ultrasound for suspected appendicitis during pregnancy. J. Magn. Reson. Imaging [Internet] 2008 [cited 2015 Dec 14];28:428-33. Available from: http://www.ncbi.nlm.nih.gov/pubmed/18666160

[14]EAES. Consensu conference Appendicitis [Internet]. Available from: http://eaes.multilearning.com/eaes/\#!*menu=6*brow seby $=4 *$ sortby $=1 *$ media $=1 *$ ce_id $=807 *$ ces_id $=642$ 4

[15]McGory ML, Zingmond DS, Tillou A, Hiatt JR, Ko CY, Cryer HM. Negative appendectomy in pregnant women is associated with a substantial risk of fetal loss. J. Am. Coll. Surg. [Internet] 2007 [cited 2015 Dec 14];205:534-40. Available from: http://www.ncbi.nlm.nih.gov/pubmed/17903726

[16]Sadot E, Telem DA, Arora M, Butala P, Nguyen SQ, Divino CM. Laparoscopy: a safe approach to appendicitis during pregnancy. Surg. Endosc. [Internet] 2010 [cited 2015 Dec 14];24:383-9. Available from: http://www.ncbi.nlm.nih.gov/pubmed/19551438

[17]Walker HGM, Al Samaraee A, Mills SJ, Kalbassi MR. Laparoscopic appendicectomy in pregnancy: a systematic review of the published evidence. Int. J. Surg. [Internet] 2014 [cited 2015 Dec 14];12:1235-41. Available from: http://www.ncbi.nlm.nih.gov/pubmed/25219891

[18]Cheng H-T, Wang Y-C, Lo H-C, Su L-T, Soh $\mathrm{K}-\mathrm{S}$, Tzeng C-W, et al. Laparoscopic appendectomy versus open appendectomy in pregnancy: a population-based analysis of maternal outcome. Surg. Endosc. [Internet]. 2015 [cited 2015 Dec 14];29:1394-9. Available from: http://www.ncbi.nlm.nih.gov/pubmed/25171885 